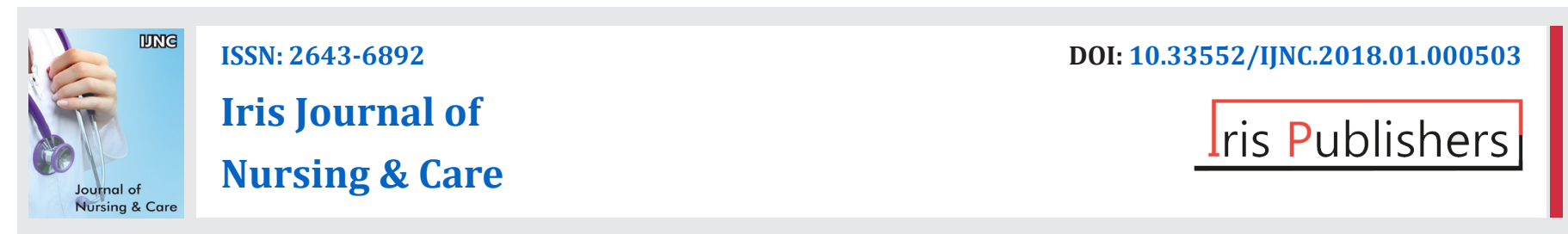

Research Article

Copyright (C) All rights are reserved by Ibrahim Yahya Alhakami

\title{
Exploring the Factors Influencing Nurse's Work Motivation
}

\author{
Ibrahim Yahya Alhakami ${ }^{1 *}$ and Omar Ghazi Baker ${ }^{2}$ \\ ${ }^{1}$ Department of Nursing Administration \& Education, College of Nursing, King Saud University, Riyadh, Kingdom of Saudi Arabia \\ ${ }^{2}$ Department of Nursing Administration \& Education, College of Nursing, King Saud University, Riyadh, Kingdom of Saudi Arabia
}

*Corresponding author: Ibrahim Yahya Alhakami, Jeddah Psychiatric Hospital, PO Box 1276, Jeddah 21431- Saudi Arabia, Al Mahjar Street, Jeddah, Kingdom of Saudi Arabia.

\author{
Received Date: October 29, 2018 \\ Published Date: November 21, 2018
}

\begin{abstract}
Work motivation is a key to emerge and enhance the nurse's satisfaction and their work performance. Accordingly, the factors that affect the work motivation among nurses became essential instruments to modify and shape the work behaviors of the nurses and its consequences. Thus, the current study aims to explore and describe the factors that are influencing the nurse's work motivation in Jeddah, Kingdom of Saudi Arabia (KSA). Cross-sectional, descriptive exploratory design is used with 300 registered nurses who were selected by stratified proportionate random sampling technique from King Abd El Aziz governmental hospital, Jeddah, KSA. The data was collected by Motivation at Work Questionnaire (MWQ), which included five sections; four was developed by Toode et al. in 2015, and one was developed by Warr in 1979. Concerning nurses' personal factors that affecting work motivation, a greater part of the study subjects has a significantly higher positive perception in work shared values and the recognition of their influence on work. As well, they have a high perception of intrinsic job motivation which considered a strong personal work motivator. The study subjects perceived higher order need strength and determined their work priorities carefully. Additionally, they have a high positive perception of intrinsic job characteristics. Besides, the nurses have a significantly higher level of satisfaction in all items within their job and life with a fair level of happiness. But, they also, have a high self-rated anxiety level which is negatively affected their work motivation. For organizational factors, a few percent's of the nurses have some needs in their working condition such as a need for flexible working hours, followed by a need for changing shift with someone else.

Conclusion: There are personal and organizational factors that are influencing the nurse's work motivation in Jeddah, which should be met and considered by nursing management.

Recommendations: It is very important to recognize the factors that affecting the nurse's work motivation, to deliver a motivational plan for promoting positive factors and overcoming the negative ones. Work motivation and its factors should be integratedinto nursing curricula. In KSA; work motivation among nurses is a crucial tool to manage nurses' shortage, retention, migration and work leave.

Further Studies: It Should be Concerned Investigation of the relationship between the nurses' work motivation and their performance. Also, assessment of hospital work incentive system in KSA. Further, development of valid and reliable tools to measure work motivation with its factors among the nurses, and replication of the study using longitudinal design.
\end{abstract}

Keywords: Work Motivation; Factors; Nurses

\section{Introduction}

Nursing is a core job in the health care system, but there is an evident shortage of nursing staff in the majority of Arabian countries. Therefore, considering the nurses' psychological needs, job satisfaction and motivation is a significant issue for maintaining the nurse's retention in the organization. There is an extreme need nationally and internationally for investigating nurses' work motivation and its factors which have a direct effect on nursing workforce's preservation, performance and consequently patient's outcomes. Identification such data is necessitated for establishing suitable work motivation methodologies to improve nurses' achievement and decrease their work turnover. Exploration of this concern will represent implications for the advancement and enhancement of administration and management in nursing and the field as a whole [1-4].

Nurses face series difficulties in their work, such as work overload, nursing errors, unstable nursing image, job demotivation, and job discrepancies. All are obstacles which faced nursing management at several health institutions. Such problems 
have a serious negative outcome on the nurse's accomplishment and consequently, have significant dangerous results in patient care. These obstacles are neither safe nor high-quality, nor patientcentered [1,3,5]. To manage those dilemmas and challenges, the nurse manager requires regular estimating and realizing of health workforce emotional needs and motivates them effectively. Motivation and its factors are effective management tools to attract, retain, enhance, and improve nurses' performance. Basu et al. in 2012 applied a research study about "Comparative Performance of Private and Public Healthcare Systems in Low- and MiddleIncome Countries: A Systematic Review." The authors found that any healthcare organizations have to be efficient, accountable, and medically effective by preparing healthcare professionals' motivation plan to develop and maintain their work satisfaction. Therefore, nurses will be kept in their work and their shortage will be overcome [2,6-8].

Work motivation is "a prerequisite for better organizational performance." It was illustrated as "the processes that account for an individual's intensity, direction, and persistence of effort toward attaining a goal." As a general rule, "motivation stems from a need which could fulfill, and this, in turn, leads to a specific behavior" [9-11]. Work motivation has several factors that can be positively or negatively affecting it. These factors define as "a set of energetic forces that originate both within as well as beyond an individual's being, to initiate work-related behavior, and to determine its form, direction, intensity, and duration" [11]. Nurse Managers should be aware of human psychology in work that deals with internal or external energies and influences the nurse employee work motivation. The internal energies are representing in personal characteristics and lead to huge diversity in work motivation level from employee to employee. Furthermore, those internal forces are including the employee competencies and talents that are used in the job. As regards the external factors of work motivation, organizational environment, work policies, teamwork, supervision methods, workplace climate, assignments' types, and communication channels are considering most apparent external dynamics that clearly influencing work motivation. This diversity in work motivation factors is increased and decreased according to nature and criteria of employees' abilities and personalities. Those factors definitely affect employee behaviors and manner of work in general. Accordingly, work motivation became an essential instrument to adjust and tailor employee behaviors and its consequences [12-16].

According to self-determination theory, there are five groups of work motivation classification which clarified more profoundly by Gagne in 2010. Gagne stressed that enhancing work motivation between the employees can easily happen through influencing the five subtypes which occupied and tailored employees' motivation in any workplace. the five subtypes are Amotivation, Extrinsic Motivation, Intrinsic Motivation, Introjected Motivation, and Identified Motivation [3,13].

Amotivation is referring to the absence of any motivation, thus, the employees not directed to do certain behaviors or do any action to stop the behavior. Extrinsic Motivation is the slightest self-determined side, and involves the behaviors of obedience, for external incentives and staying away from a penalty at work. Also, it includes positive or negative work condition and circumstances. Intrinsic Motivation points to the employees' interesting and pleasure in doing the job assignments. It is the main self-determined category and induced a grand self-contentment and work selfsatisfaction. Nurses who are internally and inherently motivated will demonstrate enjoyable work performance. Moreover, Introjected Motivation originates with the large involvement of the ego of the employee and his/her task assessment and valuing which produces the needed performance. Inner employee values and beliefs have an observed effect on high or low work achievement. Besides, the Identified Motivation is focusing on the missions that happen throughout personal consciousness, understanding, desires, and self-belief, because the employees know the importance and worth of the assigned job and its activities. Nurses with a high level of identified motivation, approximately are looking for work that assists them to accomplish their targets in life and matching their values $[3,13,17,18]$. Therefore, work motivation and its factors are the main aspects in practicing nursing management, since those concepts guide nurses' execution and capabilities to do work intentions. In sum, the internal or external motives encompass an apparent force on managing nurses' work behaviors.

Based on the previous self-determination theory, work motivation factors in nursing practice are accombined with different emotional responses and behaviors. Those responses are significantly influenced by the individual background, beliefs, and thinking that are called internal or personal factors [19]. As well, it also, affected by the thinking process which included the personal views and evaluations to self in contrast with other peers in work. As a result, work motivation is derived from the one's favorites, needs, own values, personal priorities and background factors (such as age, sex, social status, knowledge, skills, education, and position) $[3,19,20,21]$. For example, currently, by increasing the age of the nurse, the experience is increased and as well, the value for economic benefits is enhanced, compared by a nurse with young age. So, increasing in the period of work experience is linkedwith increasing in the work motivation and thus improving job position. Hence, nurses' gender, marital status, priorities, needs have great effects on their level of work motivation. Certainly, all those factors would be reflectedin shaping the nurses' work motivation level and their performance features [10,22-24].

Pertaining to external work motivation factors, they are included several of the external stimuli that are outside the employees which present in the working condition $[18,19]$. The workplace should be congruent and supported the employees' needs and preferences. A lot of evidence reported that work motivation is increased and retained among employees, by maintaining positive workplace construction and work supervision. Appreciation, orientation, assignments, communications, accountabilities, policies and procedures, teamwork and staff developmentare considered stronger organizational factors that affect nurse's work motivation $[3,25,26]$.

\section{The significance of the study}

In KSA, and particularly in Jeddah, the local health care system lacks sufficient workforce in the nursing field. Nurses' 
work motivation and investigation of its related factors can be a significant solution to achieve nurses' retention and satisfaction in their work. Worldwide, data regarding nurses' motivation and its factors is limited. So, guidelines for developing and sustaining a motivated workforce in nursing are still missing. Therefore, the current study was implemented to explore and describe work motivation factors among nurses in Jeddah. It put a grass root data for understanding those important aspects about nurses' psychological needs. This study shed some light on the value of work motivation and its correlated factors in the nursing work, then, it may be easier to develop a work motivation plan with suitable motivational strategies among nurses.

\section{Research Question}

What are the factors that are influencing nurse's work motivation in Jeddah, KSA?

\section{Method}

\section{Settings and sampling}

Cross-sectional, descriptive exploratory design is used with 300 registered nurses who were selected by stratified proportionate random sampling technique from King Abd El Aziz governmental hospital, Jeddah, KSA. The minimal sample size estimated by open epidemiological statistical information program [27] was 253 from the total 851 of registered nurses. Therefore, the researcher selected 300 nurses to avoid any disturbance in subjects' compliance in data collection or withdraw errors. Stratified proportionate sampling technique was used to select nurses from the nursing departments, then, systematic random sampling approach was used inside each department for recruiting the nurses in the study sample. The eligible criteria for selecting the nurses were: registered nurses, both sexes, work experience is at least six months; complete the initial training in the hospital; being present at the hospital during the time of data collection, and voluntarily consenting to participate in the study. The Institutional Review Board (IRB) of King Saud University (KSU) and ethical committee approvals were obtained on the research proposal. Permission to conduct this study was officially obtained from the respective principal of the mentioned setting. For data collection, subjects were asked to fill a self-report questionnaire on an individual basis. Participants were reassured for data confidentiality by using anonymity procedure.

\section{Study tool}

Motivation at work questionnaire, which included five sections: the first three and fifth sections are: questions and scales for measurements of work motivation personal factors. It involved nurses' background questions, shared values with the organization and society scale, individual influence on work scale and measurementof the organizational factors which is representing by working conditions scale [3]. The fourth section is also an internal and personal factor measurement which is Intrinsic Job Motivation Scale (IJMS) [28].

Section 1: Nurses' background factors instrument which involved: personal factors about age, gender, social status, and qualification, working profile, duration of attendance professional training, primary work area, staff position, years of experience, working schedule of shifts, and type of care provided. It is represented by fourteen questions which varied between open and multiple-choice questions. This tool was developed by Toode in 2015 [3].

Section 2: Nurses' shared values scale which directed to measure nurses' personal favorites about a variety of needs and values which are linked with work motivation. It included five measurement statements against 5-point Likert scale responses which are ranged between strongly disagree and strongly agree [3].

Section 3: Individual influence in work scale which represented one dimension of organizational factors that included three items measured through 5 points Likert scale and ranged from $1=$ none and $5=$ total $[3]$.

Section 4: Intrinsic Job Motivation Scale (IJMS) which was developed by Warr et al. [21], for measuring some work attitudes and internal psychological status of the employee. It involved eight sub-scales of measurement: work involvement (6 items), intrinsic job motivation (6 items), higher order need strength (6 items), perceived intrinsic job characteristics (10 items). Furthermore, job satisfaction (10 items), life satisfaction (15 items), happiness (1 item) and finally, self-rated anxiety (6 items). The answer was ranged for each part by a different separate Likert scale in a specific card response [28].

Section 5: Working conditions instrument included questions about the working environment and work organization. It included four questions which varied between open and multiple-choice questions. These questions involved two about the workload in the hospital and any other healthcare place and the other two questions about working schedules and opportunity for flexible work time [3].

Permission for using of each section of the study tool was obtained from the original author by email via in March 2017. The pilot study was conducted on 33 nurses from the mentioned setting but excluded from the study sample. The pilot study was done to test tool clarity and feasibility and no modifications needed. Validity was rechecked by a jury of experts in nursing education, psychiatry, and mental health nursing and nursing management departments. Reliability was re-tested by Cronbach's alpha coefficient statistical test which revealed $>0.7$.

\section{Data Analysis}

Data was entered, coded, calculated and analyzed using a PC with Statistical Packages for Social Science (SPSS, 20), Version 10.0 for Windows. The results were estimated, tabulated \& calculated using numbers, percentage, and arithmetic mean and standard deviation.

\section{Result}

\section{Nurses' profile and background (Personal factors)}

Table 1 illustrates that the greater part of nurses is females (93\%), with considerable proportion (46\%) of younger nurses who aged $<30$ years. As well, the percent of the nurses who indicate that they are living with others is more than one-half of the study subjects (54.0\%). Exactly three-quarters (75\%) of the participants 
have bachelor qualification. Noticeably proportion of nurses (35.7\%) pass in staff training for $2-4$ days and only $21.3 \%$ of them pass this training but within 5-7 days.

Table 1: Nurses' profile and background as presented by percentages.

\begin{tabular}{|c|c|c|}
\hline \multirow[t]{2}{*}{ Profile Items } & \multicolumn{2}{|c|}{ Registered nurses $\mathrm{N}=300$} \\
\hline & No & $\%$ \\
\hline \multicolumn{3}{|l|}{ Gender: } \\
\hline Male & 21 & $7.0 \%$ \\
\hline Female & 279 & $93.0 \%$ \\
\hline \multicolumn{3}{|l|}{ Age category } \\
\hline$<30$ years & 130 & $45.9 \%$ \\
\hline $30 \leq 40$ years & 97 & $34.3 \%$ \\
\hline$\geq 40$ years & 56 & $19.8 \%$ \\
\hline \multicolumn{3}{|l|}{ Social status: } \\
\hline Living alone & 138 & $46.0 \%$ \\
\hline Living with others & 162 & $54.0 \%$ \\
\hline \multicolumn{3}{|l|}{ Qualifications: } \\
\hline Vocational diploma from medical school & 40 & $13.3 \%$ \\
\hline $\begin{array}{l}\text { Specialized education from healthcare } \\
\text { college }\end{array}$ & 8 & $2.7 \%$ \\
\hline Bachelor's degree & 225 & $75.0 \%$ \\
\hline Master's degree & 4 & $1.3 \%$ \\
\hline Diploma & 23 & $7.7 \%$ \\
\hline \multicolumn{3}{|l|}{ Training duration: } \\
\hline None & 39 & $13.0 \%$ \\
\hline 1 day & 42 & $14.0 \%$ \\
\hline 2-4 days & 107 & $35.7 \%$ \\
\hline 5-7 days & 64 & $21.3 \%$ \\
\hline 8-10 days & 23 & $7.7 \%$ \\
\hline 11 days or more & 25 & $8.3 \%$ \\
\hline
\end{tabular}

\section{Nurses' workplace profile: (Personal and Organizational} factors)

Table 2 clarifies that the majority of the study sample (77\%) have their primary work area in intensive care, and $(20.3 \%$, $23.3 \%, 18.3$, and $15 \%$ ) of them come from surgical, medical and emergency care units. For staff position, almost all of the study subjects $(89.3 \%)$ are bedside nurses, while, about two-thirds of them $(62.3 \%)$ provide intensive care in nature. A great percentage of the nurses $(70.8 \%)$ have rotating day and night shifts. While approximately all of the subjects (95.7\%) mentioned that they have direct interaction with patients.

Table 2: Nurses' workplace profile as presented by number and percentag.

\begin{tabular}{|c|c|c|}
\hline Profile Items & \multicolumn{2}{|c|}{ Registered nurses $\mathbf{N = 3 0 0}$} \\
\hline & No & $\%$ \\
\hline Gender: & & \\
\hline Male & 21 & $7.0 \%$ \\
\hline Female & 279 & $93.0 \%$ \\
\hline Age category & & \\
\hline$<30$ years & 130 & $45.9 \%$ \\
\hline $30 \leq 40$ years & 97 & $34.3 \%$ \\
\hline$\geq 40$ years & 56 & $19.8 \%$ \\
\hline
\end{tabular}

\begin{tabular}{|c|c|c|}
\hline Social status: & & \\
\hline Living alone & 138 & $46.0 \%$ \\
\hline Living with others & 162 & $54.0 \%$ \\
\hline Qualifications: & & \\
\hline $\begin{array}{c}\text { Vocational diploma from medical school } \\
\text { Specialized education from healthcare } \\
\text { college }\end{array}$ & 40 & $13.3 \%$ \\
\hline Bachelor's degree & 225 & $2.7 \%$ \\
\hline Master's degree & 4 & $1.3 \%$ \\
\hline Diploma & 23 & $7.7 \%$ \\
\hline Training duration: & & \\
\hline None & 39 & $13.0 \%$ \\
\hline 1 day & 42 & $14.0 \%$ \\
\hline 2-4 days & 107 & $35.7 \%$ \\
\hline 5-7 days & 64 & $21.3 \%$ \\
\hline 8-10 days & 23 & $7.7 \%$ \\
\hline 11 days or more & 25 & $8.3 \%$ \\
\hline
\end{tabular}

Nurses' shared values in work:(Personal \& organizational factors)

Table 3 demonstrates nurses' ratings of overall shared values in work. Those ratings reflected the nurse's attitude and recognition about shared values in relation to organizational culture and workplace. Each value was settled against a descending scale order, out of a total score of seven. The highest agreement score was recorded for the nurses who report "feeling proud to tell people what specialty or profession they are working in" $(6.2 \pm 1.14)$. Followed by the mean score for"feeling proud to tell people what institution they are working at" $(5.9 \pm 1.17)$ and then, "sharing the values and beliefs of this hospital" $(5.9 \pm 1.14)$ was taken place. The lowest mean score was reported by the nurses regarding: the managers in their work who understand the needs of the employees to meet their family responsibilities $(5.0 \pm 1.67)$. Generally, there is a positive perception regarding the shared values in work (Total mean = 5.7) among study subjects.

Table 3: Nurses' shared values in the work as presented by mean and standard deviation.

\begin{tabular}{|c|c|}
\hline \multirow[t]{2}{*}{ Shared values at work items } & $\begin{array}{c}\text { Registered nurses } \\
\mathbf{N}=\mathbf{3 0 0}\end{array}$ \\
\hline & Mean \pm SD \\
\hline $\begin{array}{l}\text { I am proud to tell people what specialty or } \\
\text { profession I am working in }\end{array}$ & $6.1 \pm 1.14$ \\
\hline $\begin{array}{l}\text { I am proud to tell people what institution I am } \\
\text { working at }\end{array}$ & $5.9 \pm 1.17$ \\
\hline I share the values and beliefs of this hospital & $5.9 \pm 1.14$ \\
\hline $\begin{array}{l}\text { People working here are encouraged to develop } \\
\text { themselves }\end{array}$ & $5.5 \pm 1.44$ \\
\hline $\begin{array}{l}\text { Managers here are understanding about } \\
\text { employees having to meet family responsibilities }\end{array}$ & $5.0 \pm 1.67$ \\
\hline Total & $5.7 \pm 1.3$ \\
\hline
\end{tabular}

\section{Nurses' perception of their influence on work (Personal factors)}

Table 4 clarifies the mean scores for nurses' perception toward their influence on work which ranged between 1 to 5 scores. Remarkably, the nurses mentioned the same considerable 
recognition level about their influence on what tasks to do and the influence on intensity (pace) of work $(3.6 \pm 0.80)$. It is apparent that there is a high perception among the subjects as regards their influence on work (Mean above 3).

Table 4: Nurses' perception of their influence on work as presented according to the type of hospital by mean and standard deviation.

\begin{tabular}{|c|c|}
\hline \multirow{2}{*}{ Influence on work items } & $\begin{array}{c}\text { Registered nurses } \\
\mathbf{N}=\mathbf{3 0 0}\end{array}$ \\
\cline { 2 - 2 } & Mean \pm SD \\
\hline Influence on what tasks to do & $3.6 \pm 0.80$ \\
\hline Influence on how to do the work & $3.5 \pm 0.84$ \\
\hline Influence on intensity (pace) of work. & $3.6 \pm 0.80$ \\
\hline Total & $3.6 \pm 0.80$ \\
\hline
\end{tabular}

\section{Intrinsic Job Motivation}

\section{Nurses' perception of their involvement in work: (Personal factors)}

Table 5 displays nurses' perception of their involvement in work. Out of a maximum of seven scores, the highest score was recorded by the study subjects about their feeling of the importance of their job (6.4 \pm 1.09$)$, while the latest mean score was mentioned regarding "hate to be on the dole" $(4.9 \pm 1.85)$. On the whole, the registered nurses have high perception level as regards their involvement in work (Total mean= 5.7).

Table 5: Nurses' perception of their involvement in work as presented by mean and standard deviation.

\begin{tabular}{|c|c|}
\hline \multirow{2}{*}{ Involvement in Work Items } & $\begin{array}{c}\text { Registered nurses } \\
\mathbf{N}=\mathbf{3 0 0}\end{array}$ \\
\cline { 2 - 2 } Hean \pm SD \\
\hline $\begin{array}{c}\text { Having a job is very important for me } \\
\text { do }\end{array}$ & $6.4 \pm 1.09$ \\
\hline $\begin{array}{c}\text { I would soon get very bored if I had no work to } \\
\text { prefer to work }\end{array}$ & $5.9 \pm 1.31$ \\
\hline $\begin{array}{c}\text { If unemployment benefit were high, I would still } \\
\text { involve work }\end{array}$ & $5.9 \pm 1.33$ \\
\hline $\begin{array}{c}\text { Even if I won a great deal of money on the pools, I } \\
\text { would continue to work somewhere }\end{array}$ & $5.9 \pm 1.22$ \\
\hline I should hate to be on the dole & $4.9 \pm 1.85$ \\
\hline Total & $5.7 \pm 1.4$ \\
\hline
\end{tabular}

\section{Nurses' intrinsic job motivation:(Personal factors)}

Table 6 reveals the nurse's perception about their intrinsic job motivation as presented by mean and standard deviation. High mean scores (above 5) were reported by the nurses for all scale items which indicating their high intrinsic job motivation level. The highest mean score was recorded for "trying to think of ways to do their job effectively" (6.4 \pm 0.92$)$, followed by "the feeling a sense of personal satisfaction when doing their job well" $(6.3 \pm 1.25)$. "I take pride in doing my job as well as I can", "I like to look back on the day's work with a sense of a job well done" and "I feel unhappy when my work is not up to my usual standard", all those items got the same mean scores $=6.2$. "My opinion of myself goes down when I do this job badly", took the least mean score $=5.9$. Globally for all scale items, the total mean score is 6.2 which indicate high intrinsic job motivation among the study participants.

Table 6: Nurses' intrinsic job motivation as presented by mean and standard deviation.

\begin{tabular}{|c|c|}
\hline \multirow{2}{*}{ Intrinsic Job Motivation Items } & $\begin{array}{c}\text { Registered nurses } \\
\mathbf{N}=\mathbf{3 0 0}\end{array}$ \\
\cline { 2 - 2 } & Mean \pm SD \\
\hline I try to think of ways of doing my job effectively & $6.4 \pm 0.92$ \\
\hline $\begin{array}{c}\text { Feel a sense of personal satisfaction when I do } \\
\text { this job well }\end{array}$ & $6.3 \pm 1.25$ \\
\hline $\begin{array}{c}\text { I take pride in doing my job as well as I can } \\
\text { of a job well done }\end{array}$ & $6.2 \pm 1.12$ \\
\hline $\begin{array}{c}\text { I like to look back on the day's work with, a sense } \\
\text { usual standard }\end{array}$ & $6.2 \pm 1.00$ \\
\hline $\begin{array}{c}\text { I feel unhappy when my work is not up to my } \\
\text { job badly }\end{array}$ & $6.2 \pm 1.15$ \\
\hline My opinion of myself goes down when I do this & $5.9 \pm 1.53$ \\
\hline Total & $6.2 \pm 1.2$ \\
\hline
\end{tabular}

\section{Nurse's perception of higher order need strength: (Personal factors)}

Table 7 illustrates the study subject's perception of higher order need strength as presented by a mean and standard deviation. The scale is measured out of a maximum of seven scores. The highest ordered need was reported by study participants was regarding "have the opportunity to learn new things" $(6.4 \pm 0.95)$, followed by "using the own skills to the maximum" (6.3 \pm 1.03$)$, and "achieving something that represents the value" $(6.3 \pm 0.97)$ took place. The least mean score was rated by the nurses was about "the opportunity to make own decisions" $(6.1 \pm 1.14)$. It was noticed that there is a high positive perception toward all types of employee needs in the organization among the study subjects.

Table 7: Nurses' perception of higher order need strength as presented by mean and standard deviation.

\begin{tabular}{|c|c|}
\hline \multirow{2}{*}{ Perceiving Higher Order Need Strength Items } & $\begin{array}{c}\text { Registered nurses } \\
\text { N=300 }\end{array}$ \\
\cline { 2 - 2 } & Mean \pm SD \\
\hline The opportunity to learn new things & $6.4 \pm 0.95$ \\
\hline Using your skills to the maximum & $6.3 \pm 1.03$ \\
\hline Achieving something that you value & $6.3 \pm 0.97$ \\
\hline Challenging work & $6.2 \pm 1.07$ \\
\hline Extending your range of abilities & $6.2 \pm 1.19$ \\
\hline The opportunity to make your own decisions & $6.1 \pm 1.14$ \\
\hline Total & $6.25 \pm 1.05$ \\
\hline
\end{tabular}

\section{Nurse's perception of intrinsic job characteristics: (Personal factors)}

Table 8 discloses nurses' perception of intrinsic job characteristics. The mean scores for describing the intrinsic job characteristics and are ranging from one score for its total absence up to a maximum of five scores for total availability. The highest mean score was recorded among the nurses was about "the amount of the given responsibility" $(4.2 \pm 0.80)$ followed by "doing a whole 
and complete piece of work" $(3.9 \pm 0.98)$ and "the opportunity to use their abilities $(3.9 \pm 0.96)$. The least perception means score in intrinsic job characteristics scale was in relation to "the freedom to choose the method of working", mean $=3.3$. In general, the table represents high nurses' perception of intrinsic job characteristics ( Total $=3.71 \pm 1.09$ ) mean is above 3 .

Table 8: Nurses' job satisfaction among nurses as presented by mean and standard deviation.

\begin{tabular}{|c|c|}
\hline \multirow{2}{*}{ Job Satisfaction Items } & $\begin{array}{c}\text { Registered Nurses } \\
\mathbf{N}=\mathbf{3 0 0}\end{array}$ \\
\cline { 2 - 2 } Your immediate boss & Mean \pm SD \\
\hline The amount of responsibility you are given & $5.1 \pm 1.45$ \\
\hline Your fellow workers & $5.1 \pm 1.47$ \\
\hline Your opportunity to use your abilities & $5.1 \pm 1.46$ \\
\hline Your rate of pay & $5.0 \pm 1.46$ \\
\hline The recognition you get for good work & $4.9 \pm 1.62$ \\
\hline The physical work conditions & $4.8 \pm 1.52$ \\
\hline Industrial relations between management and \\
workers un your firm & $4.6 \pm 1.43$ \\
\hline The freedom to choose your method of working & $4.6 \pm 1.60$ \\
\hline Your chance of promotion & $4.5 \pm 1.74$ \\
\hline Total & $4.86 \pm 1.55$ \\
\hline
\end{tabular}

\section{Nurses' job satisfaction: (personal factors)}

Table 9: Nurses' perception of intrinsic job characteristics as presented by mean and standard deviation.

\begin{tabular}{|c|c|}
\hline \multirow{2}{*}{$\begin{array}{c}\text { Items of Perceiving Intrinsic Job } \\
\text { Characteristics }\end{array}$} & $\begin{array}{c}\text { Registered nurses } \\
\mathbf{N = 3 0 0}\end{array}$ \\
\cline { 2 - 3 } & Mean \pm SD \\
\hline The amount of responsibility you are given & $4.2 \pm 0.80$ \\
\hline Doing a whole and complete piece of work & $3.9 \pm 0.98$ \\
\hline Your opportunity to use your abilities & $3.9 \pm 0.96$ \\
\hline $\begin{array}{c}\text { Being able to judge your work performance, the } \\
\text { right way, when doing the job }\end{array}$ & $3.8 \pm 1.00$ \\
\hline $\begin{array}{c}\text { The amount of variety in your job } \\
\text { The feeling of doing something which is not } \\
\text { trivial, but worthwhile }\end{array}$ & $3.7 \pm 1.10$ \\
\hline The recognition you get for good work & $3.7 \pm 1.05$ \\
\hline The attention paid to suggestions you make & $3.6 \pm 1.19$ \\
\hline Your chance of promotion & $3.5 \pm 1.17$ \\
\hline The freedom to choose your method of working & $3.3 \pm 1.38$ \\
\hline Total & $3.71 \pm 1.09$ \\
\hline
\end{tabular}

Table 9 describes the level of nurses' job satisfaction as presented by mean and standard deviation. The mean scores of the scale are ranged from 1 score for extremely dissatisfied up to a maximum of 7 scores for extremely satisfied. The highest mean scores of the items in nurses' job satisfaction scale were ranked as regarding to 1- their satisfaction of immediate boss as a first rank (5.1 \pm 1.45$), 2$ - the amount of given responsibility as a second rank
(5.1 \pm 1.47$)$ and 3- the fellow workers as a third rank $(5.1 \pm 1.46)$. While the low mean score as regards the nurses' job satisfaction was about the chance of promotion $(4.5 \pm 1.78)$.In general, the table reveals that nurses have a significantly higher level of job satisfaction. (Total $=4.86 \pm 1.55$ ), mean is above 4 .

\section{Nurses' Life satisfaction: (personal factors)}

Table 10 demonstrates nurses' level of life satisfaction as presented by mean and standard deviation. The highest mean scores of life satisfaction level among nurses were recorded about the received education and what accomplished in life (5.6 \pm 1.20 and $5.6 \pm 1.17)$, family life $(5.5 \pm 1.57)$, present health status $(5.5 \pm 1.28)$ and the present government (5.5 \pm 1.36$)$. Furthermore, the high mean score in life satisfaction scale among nurses was clearly observed as regards "KSA's reputation in the world today" (5.5 \pm 1.40$)$. But the lowest mean score of life satisfaction scale among nurses was about the house or flat of living $(4.5 \pm 1.66)$. In general, the nurses have high perceiving level of life satisfaction (Total mean $=5.3 \pm 1.4$ ), mean is above 4 .

Table 10: Nurses' life satisfaction as presented by mean and standard deviation.

\begin{tabular}{|c|c|}
\hline $\begin{array}{c}\text { Items for Perceiving Life } \\
\text { Satisfaction }\end{array}$ & Megistered nurses N=300 \\
\hline The education you have received \\
\hline What you are accomplishing in life & $5.6 \pm 1.20$ \\
\hline Your family life & $5.6 \pm 1.17$ \\
\hline Your present state of health & $5.5 \pm 1.57$ \\
\hline What the future seems to hold for you & $5.5 \pm 1.28$ \\
\hline The present government & $5.4 \pm 1.32$ \\
\hline Your social life & $5.5 \pm 1.36$ \\
\hline The moral standard and values in KSA \\
today
\end{tabular}

\section{Nurses' happiness}

Figure 1 illustrates nurses' level of happiness in work. The majority of study participants (79.3\%) was fairly happy, while who expressed very happy were only $(10.8 \%)$, while, about the same percent $(10 \%)$ of the subjects was not too happy. 


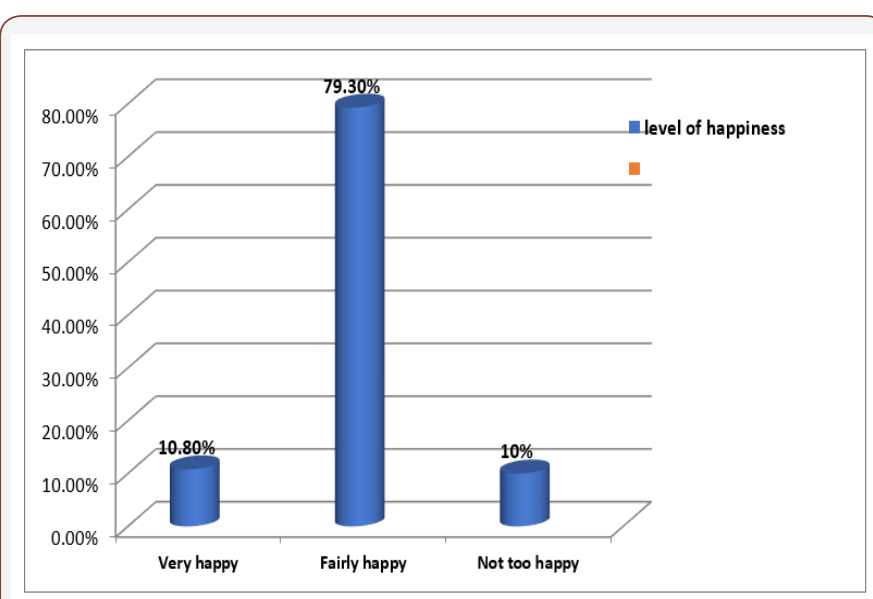

Figure 1: Nurses' level of happiness as presented by percentages.

\section{Nurses' self-rated anxiety}

Table 11 shows nurses' self-rated anxiety as presented by mean and standard deviation. The nurse's mean scores of the self-rated anxiety were expressed on the scale ranging from one score for being not at all concerned about it up to seven scores for extremely worried. It was noticed that the highest mean score among nurses

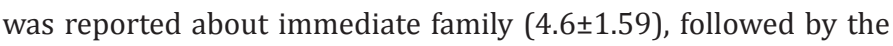
KSA's economic future $(4.5 \pm 1.74)$. On the other hand, the lowest mean score among nurses was reported about growing old. In general, there is an observed high self-rated anxiety level among study subjects (Total $=4.6 \pm 1.6)$ mean is above 4 .
Table 11: Nurses' self-rated anxiety as presented by mean and standard deviation.

\begin{tabular}{|c|c|}
\hline Items of Self-Rated Anxiety & Registered nurses $\mathbf{N}=\mathbf{3 0 0}$ \\
\hline Immediate family & $4.6 \pm 1.59$ \\
\hline KSA's economic future & $4.5 \pm 1.74$ \\
\hline $\begin{array}{c}\text { In general, how worried or concerned do } \\
\text { you feel these days }\end{array}$ & $4.4 \pm 1.67$ \\
\hline Your health & $4.3 \pm 1.49$ \\
\hline How things are going at work & $4.3 \pm 1.50$ \\
\hline $\begin{array}{c}\text { Not having enough money for day to day } \\
\text { living }\end{array}$ & $4.2 \pm 1.65$ \\
\hline Growing old & $4.2 \pm 1.59$ \\
\hline Total & $4.6 \pm 1.6$ \\
\hline
\end{tabular}

\section{Rating of nurses' perception about work condition:} (Organizational factors)

Figure 2 reveals nurses' perceptions about working condition. Study subjects reported their recognition about working condition through their needs, the work assignment opportunities, and the benefits that provided to them at their workplace. About one-half of nurses $(43.7 \%)$ mentioned a need for flexible working hours, followed by $27.7 \%$ of them reported a need for changing shift with someone else. However, minimal percent of them $(2.3 \%, 6 \%$, and $2.7 \%$ ) commented that they require a nursery at the workplace, paternal leave and work from home during normal working hours. Generally, there are few proportions of the nurses who have some needs in their workplace.

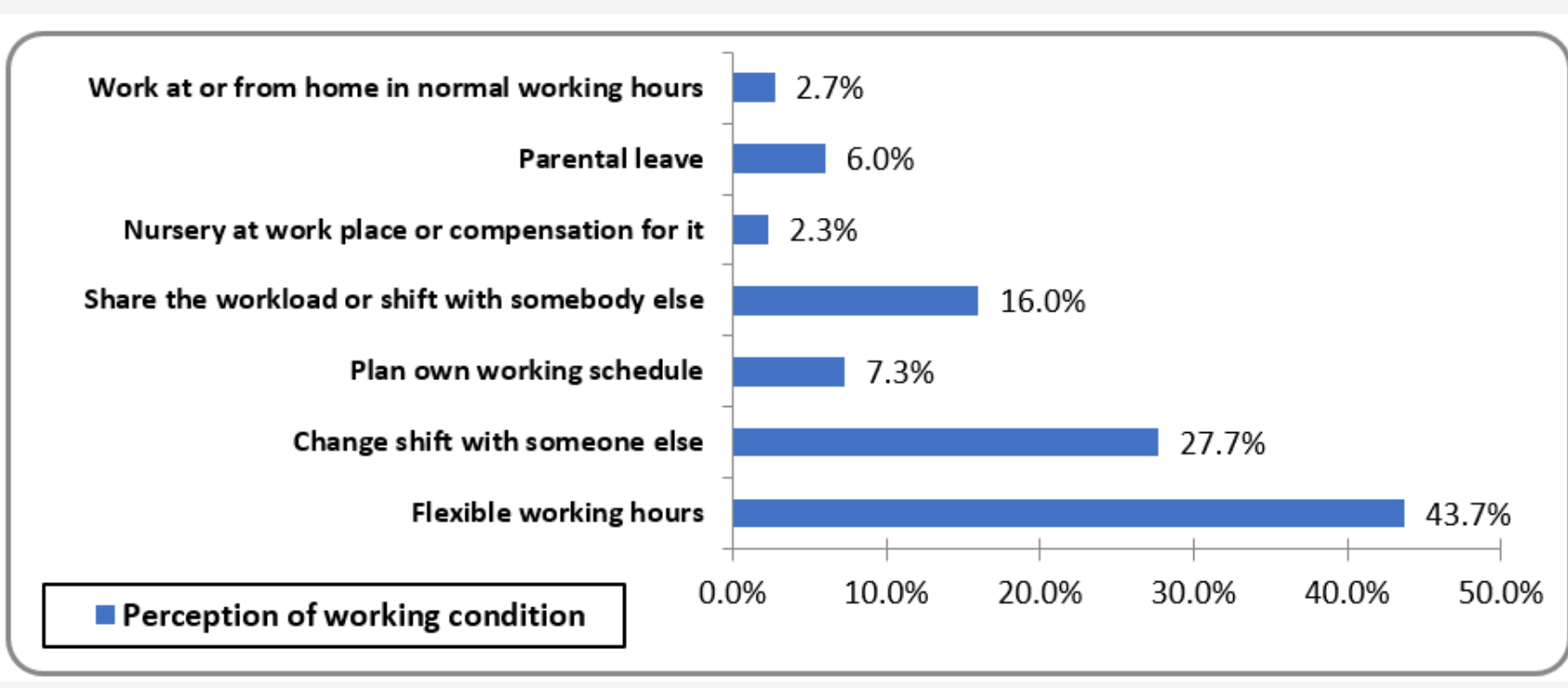

Figure 2: Nurses' perception about work condition.

\section{Discussion}

The Kingdom of Saudi Arabia (KSA) passes during a vast time of development and advancement in diverse healthcare services. Nursing work has main contributions to maintain and enhance this development. The nursing profession is the backbone of KSA healthcare employment, but it has been suffered from severe deficiency for several years, ago. Sustaining and maintaining nurses in their job, become a necessitate mission in nursing management field at KSA [6,29]. The majority of healthcare activities are greatly dependent on nurses. They have a lot of roles and responsibilities such as clinical judgment, teaching, provision of care, directing others, managing resources, researching, advising and coordinating healthcare services. Every role of those previous activities has to be effective, efficient and committed [30]. Work motivation controls nurse's work performance and affect their behaviors positively by internal and external powers. As well, it enhances their contentment, 
initiation, and satisfaction at work. Thus, nurses' work motivation is a crucial duty of nurse manager and healthcare stockholders. Nurse Manager should comprehend and manipulate all factors that affect nurses' work motivation to gain the desired nursing care achievement and obtain successful healthcare outcomes [13,26,30].

The current study provided an extraordinary view about the factors that are influencing nurse's work motivation in Jeddah, KSA. Since and consistent with literature review there are a few studies in such important aspect, particularly in KSA. The following findings provide adequate details, to answer the present research question. The revealed results that related to the personal factors which influenced nurses' work motivation showed that the majority of study participants were females in their twenties and with bachelor qualifications. Nationally and internationally, work motivation in healthcare is highly influenced by sociodemographic criteria. Hence, work motivation is an emotional work response and originated from the employee personal characteristics. It is affected by individual background and how the person thinks or believes in a work situation [19]. Additionally, the intrinsic conscious of the employee that control work motivation is depending on the personal attributes and values [20]. The current result was expected since that the bulks of KSA and worldwide nursing workforce are females with bachelor prerequisites. The current finding comes in line with Al-Mutairi in 2015 in KSA who discussed that the Saudi Kingdom has an extreme need for workforce professionals in nursing career and the hiring process puts criteria that the nursing employee should have bachelor aptitudes and with young and suitable ages [6]. Besides, youthful female nurses with well educational preparations are motivated in work than old and nonqualified nurses [10,31]. In contrast, De Cooman et al. [32] discussed that nurse's age has week correlation with their work motivation in different manners, and motivation is not determined by young or old age, this has directed to incompatible findings. Generally, almost of study participants have the feature of young age, female and acceptable and suitable educational degree to be adequately motivated in their nursing work. Age, sex, and qualifications have an apparent effect on shaping work motivation. But still, it is a great burden on KSA to preserve nurses' workforce in their positions.

As well, and supporting to existent finding, In Egypt, Abdel Halem et al. [31], clarified that males' workforce in the nursing field is not sufficient and have a limited work motivation to join nursing field. Females nurses are the majority of nursing employment and they are dominating this career. However, men in nursing work have many opportunities to be more experienced than women and they still have low motivation and they are standing with small numbers alongside feminine [10,31]. Conversely, the relationships that are involving nurses' sexual category and motivation still vague since the male number in the current study sample is too little to give a reliable result about gender support differentiation.

Also, about nurse's qualification, and matching with the current result, Al-Mutairi in 2015 and Abdel Kader in 2012 reported that there are many healthcare settings in KSA recommended the hiring of bachelor qualifications in nursing jobs. Nurses with such qualifications have the necessary knowledge and skills to meet the nursing work requirements. Competency in health and patient care is the target of all healthcare professionals and should be achieved by qualified health staff $[6,33]$. On the whole, qualification, experience, and, personality traits, are considering apparent personal aspects that can empower or inhibit work motivation among nurses.

As pertaining to training in work, a great percent of study subjects reported that they received staff training \& development with duration from two to seven days. Regardless of the training duration, all nurses mentioned that they are receiving work training which is an obvious indicator to increase staff work motivation. Congruent with this finding and in the past century, Hackman \& Oldham, in 1980, clarified that the inherent work motivation is represented in work training through three inner psychological conditions: "experienced meaningfulness of the work, experienced responsibility for work outcomes, and a knowledge of the actual results of the activities." Therefore, the knowledge, competencies, skills, and attitudes are gained by nurses during the staff training in a healthcare setting, are extremely important to evoke their work motivation. Staff development by several approaches of training tends to prepare the nurses for being competent, expert and carrying out their responsibilities in an optimal manner [3,34]. So, staff training is an understandable factor that enhances nurses' internal and external work motivation.

Concerning, workplace profile of the study group, as a personal and organizational factor, the present result revealed that the greater part of study subjects mentioned that they are working in intensive care units with rotating day and night's work schedule and the majority of them have direct contact with patient care. This finding is anticipated, because, nationally and internationally, many of healthcare professionals who are with proper work competency have to take years of experience in intensive care and inpatient units. When the nurses in the critical care department are alert to their crucial roles with critically ill patients, they are internally motivated as personal factors. In the same time, they are externally motivated by the duties and accountabilities, rewards and seriousness of intensive care situations as organizational factors. The current result is fitting with Weldegebriel et al. [35] who clarified that the essential attribute of the agency is the environment in considering some variations in workforce numbers, staff functions, and assignments schedules, particularly in intensive care units which fill with excellent experiences and advanced technologies [35,36]. Furthermore, in nursing work, the nurses who provide direct patient care, especially in intensive care areas, have competent experiences and hand on competencies more than the nurses who are in administrative work. Direct patient care considered a central experience for raising nurse's work motivation [37].

Dissimilar to this view, Danil et al. [38] and Jacobi [39] mentioned that workplace and its environment are varying from agency to agency, related to multiple reasons; staffing, patient interaction, schedules, and nature of healthcare services which differs from specialty to specialty. Direct patient care and critical care may have a minimal number of professionals and have several burdens. Sometimes, some nurses work in the criticalcare units but give incompetent care. Therefore, nurses' workforce tends to be 
more competent or expert according to many explanations. Usually, workplace features, are the link with personal attributes and considered personally and institutionally factors for controlling nurses' work motivation. Definitely, intensive care and direct patient care are essential experiences in workplace profile for nursing work competency and work motivation, even the current result is not congruent with some studies.

Concerning, work shared values as personal and organizational factors that are affecting nurses' work motivation. Work shared values are referring to the congruency between nurses' value system and work characteristics or conditions that are provided by the organization \& society [40]. The current study finding illustrates that the study participants have significantly higher mean scores in all items of perceiving shared values at the workplace. Thus, they expressed agreement and appreciation to all workplace elements and reflected their high work motivation. This result is similar with Weldegebriel et al. [35] and Jacobi [39] who explained that enough human and nonhuman resources and facilities, policies and supervision in a healthcare setting, lead to staff retention and motivation. Particularly nurses tend to migrate from setting to setting or abroad, due to their desire to work in safe and wellprepared place, and when they find suitable workplace preparation, they will be retained in their jobs. Additionally, according to Toode [3], high recognition of shared values with the institution and society is connected with elevated nurses' work motivation. Predominantly, positive shared values as a personal factor were coupled with high intrinsic work motivation [3]. Study subjects reported that they are proud of and appreciate their profession, workplace, and management style. They provide evidence that they have high work shared values recognition and internally motivated in their work based on such perception.

Regarding, another personal factor that is affecting work motivation among nurses; it is the nurses' perception of their influence on work. The current study result clarifies that it is apparent that nurses have elevated scores in perceiving of their influence on work, as regards: work task, how to do the task and the work intensity. Employee's recognition of their influence on work is a valuable feature to increase their work motivation. According to self-determination theory, awareness of the personal influence on work is the inner liveliness of the three motivational regulations: Intrinsic Motivation, Introjected Motivation, and Identified Motivation. The worker ties between the ego and believe the values of own achievement. So, recognition of this issue will create a source of empowerment in work. As a result, pride, high self-esteem, and self-importance will become visible. As well, when the employees experience the inner acknowledgment of their influence on work, they will be internally motivated and interested in doing the best work performance. In the same line with this result, individual awareness of own influence on work is a remarkable positive sign of employee enjoyment, better communication, empowerment, cooperation, teamwork and engagement in work tasks $[3,16,20]$. Similarly, Alshmemri in 2014 reported that the nurses in the private sector have a periodical orientation about their influence on work as regards; work details, process, and outcomes. Continuous staff announcement during the higher management meetings is good source for nurses' appreciation and Acknowledgment about the worth of their achievement. Furthermore, nurses feel more empowered, motivated and satisfied, if they found proper management methodology in staff communication about the work outcomes $[4,8,16]$. Nurses' awareness by their job tasks and their effectiveness on work is an excellent factor to expand their motivation and engagement in work.

An additional personal factor that reported by study subjects is nurses' involvement in work. The majority of nurses in the present study reported high mean scores in such a perception. Study subjects appreciated their work importance, good money deal and mentioned that they wouldn't leave their job. Involvement in work refers to which degree the employee participates, cooperates and accepts the work assignments. Besides, to which extend the employee are sharing in decision making in the agency. All are signs of employees' competency and supervisors' trust. Fitting to this point of view, Tummers et al. [40] mentioned that nurses' work involvement enhances the feeling to be a team or family member in the organization; consequently, nurses gratify the work nature and have a desire to be retained in their work. Moreover, Battistelli et al. [41], clarified that when nurses felt more work involvement, they will be more independent, autonomous and inherently motivated. Contradicting to this result, Toode [13] reported that, some employees found their involvement in work is one of job burden, which needs more responsibilities and accountabilities.

Intrinsic job motivation is a further personal factor that is affecting work' motivation among nurses and considered a strong personal motivator. Study participants have high mean scores in this factor. This result denotes that nurses have high intrinsic job motivation in work regarding their thinking to be an effective person in work, feeling a sense of personal satisfaction and being pride in doing work tasks. This outcome is supported by Dave et al. [42] who discussed that the intrinsic job motivation is an intellectual status of the workforce which enhances their capabilities to achieve work performance and desired work products. It is an excellent source of motivation and called" self-fulfilling experience". From a researcher point of view, intrinsic job motivation tends to push nurses to be interested, satisfied and productive in work. It can be evidence of job gratification. As well, it is the main cause for deciding to continue in a job among employees.

Besides, and about the next personal factor that has an obvious effect on nurses' work motivation which is the nurses' recognition of higher order need strength. It is noticeable that the nurses in the present study have a high perception score to appreciate the presence of all their needs in work. The needs that mentioned by some of the study subjects are: the opportunity to learn new things, followed by using the own skills to the maximum and, the next rank is achieving something that represents value for them. Higher order needs have a significant correspondence with nurse's ability to rank their own needs according to their beliefs and priorities. This factor is depending on individual psychosomatic conditions, for instance, nurses' evaluation of the meaning and importance of job tasks, nurses' appreciation for own abilities to carry out of work responsibilities and accountabilities and nurse's awareness 
with all task sequences. This result is harmonizing with Toode et al. $[3,13]$ who illustrated that personal priority to rank higher order need strength is associated with both internal and external nurse motivation. This relationship is increased positively with emotional status and the level of work motivation among the nurses. Similarly, Baldwin in 2017 described that strong awareness of higher order needstrength of the employees is working as a moderator and has a supporting role in job achievement and work fulfillment. But this relation is limited among the employees who with weak higher order need strength [43]. It is obvious that the nurse's perception of their higher order needs strength shows a positive correlation with their work motivation.

About the next personal factor that is affecting work motivation, which is intrinsic job characteristics as perceived by nurses. The current result illustrates that there are high mean scores among nurses in percieving intrinsic job characteristics. Evidently, they reported the highest mean score as regards the amount of the given responsibility, followed by doing a whole and complete piece of work and own opportunity to use abilities. In general, there is a positive perception of intrinsic job characteristics among study participants. Consistent with this finding, $\mathrm{Xu}$ [42] stressed that the intrinsic job characteristics are linked with constructive work experience, personal development, and teamwork cooperation. The high recognition of all components of intrinsic job characteristics is contributed to encouraging nurse's job satisfaction and motivation. Additionally, Dave et al. [44] reported that agreement on intrinsic job characteristics considered the strong factor to make powerful work motivation.

Nurses' job satisfaction and life satisfaction are the next personal factors that seriously influence nurses' motivation at work. The present result proves that nurses have a significantly higher level of satisfaction in all items within their job and life. Job satisfaction is considered a measurement of workers' contentedness with their job, whether or not they like the job. Or, it is a feeling of fulfillment or enjoyment which is the cause of work motivation $[7,16]$. Corresponding with the recent result, a study in South Africa, which conducted by Pillay in 2009 who clarified that nurses who have job satisfaction, exhibit a high level of work motivation. This satisfaction symbolized in workers' enjoyment of patient care, their rapport with peers, feeling of belonging and life satisfaction as a whole [45]. Incongruent with this point, Alshmemri in 2014 in KSA confirmed that Saudi nurses who in governmental hospitals are dissatisfied with their work. Many types of research approve the discrepancy among governmental and private sectors, at all job and life satisfaction components [4]. The discrepancy among healthcare sectors in workforce satisfaction level is a factual warning sign faced the nursing career. Professional healthcare managers have to understand all the reasons and factors for work dissatisfaction to overcome it and recognize how to facilitate work satisfaction.

In pertaining to other personal factors, there is nurses' happiness, which according to the present finding, is fair level among the majority of the study subjects. Fitting to this finding, Almalki et al. [46] reported that it is essential to the nursing manager to modify the feature of work to be a positive factor on nurses' work achievement, loyalty, and happiness. As well, workforce retention, motivation, and satisfaction are improved, particularly if the employee becomes happy. Additionally, Warr [19] denoted that the happiness, satisfaction, and motivation in work are three signs for work recognition and faithfulness which completed each other. So, they are the triangle that leads to successful outcomes for healthcare setting and patients.

The last personal factor is work-related anxiety; the existing result reveals that the nurses have a high self-rated anxiety about immediate family and their KSA's economic future. There is limited evidence that discusses nurse's self-rated anxiety in work. But globally, many pieces of evidence argued that healthcare professionals have a lot of stressors, anxiety, and frustration which are affecting negatively on work satisfaction and motivation. Anxiety is an emotion described by an unpleasant state of inner confusion, frequently comes with mal-nervous behaviors, mal-alertness, somatic complaints, and poor cognition. The feeling of anxiety in work is a negative emotion. Harmonious with this result, Abu Ruz ME, in 2014 conducted a comparison between Jordanian and Saudi nurses in relation to the impact of stress on job satisfaction. He mentioned that stress and anxiety adversely influence healthcare professionals, particularly about work future. Anxiety and stress in nursing work are growing because of the difficult nature of the nursing job. Consequently, these dangerous variables, of course, have harmful effects on work satisfaction and motivation $[4,47]$.

The frequency and distribution of anxiety are greater than before among healthcare employees in the workplace. Anxiety among nurses can disturb work performance, stability, and outcomes. As well, it can be a cause for leaving work $[4,8,13]$. Therefore, and predominantly, nurse manager should investigate the sources and reasons for job anxiety and stress among nurses to avoid them. It is clear that self-rated anxiety is the factor that has high mean score among study subjects like other factors, but it is the only factor, if it is increased, it will indicate an adverse effect on the work motivation.

Working conditions are representing the second type of factors which are regarding the external or organizational factors and affecting work motivation among nurses. According to the recent finding, the nurses reported their high recognition level of the working condition through their needs based on the work assignment opportunities, and benefits or services that provided to them at their workplace. Considerable percent of them need for flexible working hours, followed by a need for changing shift with someone else. However, the minimal percent's of them commented that they require the nursery at the workplace, paternal leave and work from home during normal working hours. Generally, all nurses who have certain needs in working condition are with few proportions. The current result highlights minimal needs of nurses, but it should be considered. Also, this result clarifies that to which extent the work condition can be a positive or a negative cause for nurse's empowerment and motivation. Matching to the current result, in South Africa, Pillay in 2009 proved that poor and lacked working conditions with the inappropriate institutional atmosphere are observable indicators for nurse's disappointment 
and decreasing nurses work satisfaction. On the other hand, Alshmemri in 2014 confirmed that; when nurses found suitable income, facilities, assignments, scheduling, constructive work climate, supportive institution management, fair policies, and cooperative teamwork, they will be highly working motivate $[4,8,45]$. Additionally, and matching with this point, Toode in 2015 and Warr in 2013 described that work motivation among nurses is greatly affected by several institutional and work condition, regarding; enough resources, supportive supervision and proper work scheduling. Therefore, the health organization should offer good salaries, rewards and proper incentive system to meet nurses' desires, needs and favorites for the employees [3,19]. Moreover, Global Health Workforce Alliance, in 2008 and Stacey, in 2011 reported that professionals felt autonomous and competent when finding adequate and prepared workplace conditions $[25,48]$.

Finally, and according to the results of some researches that conducted in KSA, the nurse's work motivation level is linked with the level of nurses' competency and productivity. It is noticeable that there are many personal or organizational factors that are influencing positively or negatively healthcare professionals' motivation in work. Closed observation, investigation, and detection of those factors is a beneficial step for any healthcare system to promote nurse work motivation in general $[4,6,49,50]$.

\section{Conclusion}

The current study highlights some personal and organizational factors that are affecting nurses' work motivation. The majority of study participants have a significantly higher positive perception as regards work shared values and their influence on work. Moreover, the study subjects have a high perception of intrinsic job motivation which considered a strong personal factor in the workplace. S well, the nurses in the study have recognition of their higher order need strength, and they determined their work priorities carefully. Additionally, they have high intrinsic job characteristics in the amount of the given responsibility, doing a whole and complete piece of work and own opportunity to use abilities. Also, the nurses have a significantly higher level of satisfaction in all items within their job and life with a fair level of happiness. But, they also, have high self-rated anxiety level which leads to a negative effect on their work motivation. A few percent's of nurses have some needs as regards the working condition such as a need for flexible working hours, followed by a need for changing shift with someone else. It is very important to recognize those personal and organizational factors among nurses to deliver a proper motivational plan for promoting the positive factors and overcoming the negative ones.

\section{Recommendation and Further Studies}

Work motivation and its factors should be integratedinto nursing curricula. In KSA; this study considers a beneficial step to determine the factors that are affecting nurses' motivation at work in Jeddah. Consequently, appropriate motivation strategies will be implemented with nurses to sustain them in their jobs. Further studies are needed such as assessment for nurses' work motivation level and the quality of patient care, Investigate the relationship between nurses' work motivation and their performance, also, assessment of hospital work incentive system in KSA, develop valid and reliable tools to measure work motivation and its factors among nurses and replication of the current study using longitudinal design.

\section{Conflict of interest}

None to declare.

\section{Funding}

This research received no specific grant from any funding agency in the public, commercial, or not-for-profit sectors.

\section{Acknowledgment}

The authors are thankful to the Deanship of Scientific Research through the Research Center at the College of Nursing, King Saud University for support of current research.

\section{References}

1. Dar S, Zehra N, Ahmad F (2014) Extrinsic Factors Strong Motivators for Nurses in the Tertiary Care Hospitals. Pakistan Journal of Medicine and Dentistry 3(1): 31-36.

2. ToodeK, RoutasaloP, Suominen T (2011) Work motivation of nurses: A literature review. International Journal of Nursing Studies 48(2): 246257.

3. Toode K (2015) Nurses' work motivation: Essence and associations. Published Academic Dissertation. University of Tampere, School of Health Sciences, Tampere University Press, Finland, pp. 9-73.

4. Alshmemri M (2014) Job satisfaction of Saudi nurses working in Saudi Arabian public hospitals. School of health sciences, discipline of nursing and midwifery. Royal Melbourne Institute of Technology published Phd thesis, Jordan University 1-33.

5. Ajayi K (2004) Leadership, Motivation, Team Work and Information Management for Organizational Efficiency. The Nigerian Journal of the Social Sciences 1-16.

6. Al-Mutairi E (2015) Healthcare Workforce Challenges in Saudi Arabia (A Brief Overview).

7. AgyepongI, Anafi P, Asiamah E, Ansah EK, Ashon DA, et al. (2004) Health worker (internal customer) satisfaction and motivation in the public sector in Ghana. International Journal of Health Planning and Management 19(4): 319-336.

8. Basu S, Andrews J, Kishore S, Panjabi R, Stuckler D (2012) Comparative Performance of Private and Public Healthcare Systems in Low- and Middle-Income Countries:A Systematic Review. PLoS Med 9(6).

9. Adjei KA, Emmanuel O, Forster OM (2016) The Impact of Motivation on the Work Performance of Health Workers (Korle Bu Teaching Hospital): Evidence from Ghana. Hospital Practices and Research1(2): 47-52

10. LambrouP, Kontodimopoulos N, NiakasD (2010) Motivation and job satisfaction among medical and nursing staff in a Cyprus public general hospital. Human Resources for Health 8:26.

11. Pinder C (2008) Work motivation in organizational behavior ( $\left.2^{\text {nd }} e d n\right)$. Psychology Press, New York, USA.

12. Deckers L (2014) Motivation; Biological, Psychological and Environmental. ( $4^{\text {th }}$ edn pp. 2-3), Pearson, Boston, US.

13. Toode K, Routasalo P, Helminen M, Suominen T (2014) Hospital nurses' individual priorities, internal psychological states and work motivation. International Nursing Review 61(3): 361-370.

14. Inceoglu I, Segers J, Bartram D(2012)Age-related differences in work motivationJournal of Occupational and Organizational Psychology 85(2): 300-329.

15. GagnéM, Forest J, Gilbert MH, Aubé C, Morin E, et al. (2010) The Motivation at Work Scale: Validation evidence in two languages. Educational and Psychological Measurement 70(4): 628-646. 
16. Attrams R (2013) Motivation and employee satisfaction: perceptions of workers in public and private health care facilities. Published Thesis, University of Ghana.pp.1-90.

17. Ormrod J (1999) Human learning. ( $3^{\text {rd }}$ edn) Upper Saddle River, PrenticeHall, New Jersey, USA.

18. Ryan RM, Deci EL (2000) Intrinsic and extrinsic motivations: classic definitions and new directions. Contemporary Educational Psychology 25(1): 54-67.

19. Warr P (2013) Jobs and job-holders: Two sources of happiness and unhappiness. In S. A. David, I. Boniwell, \& A. C. Ayers, the Oxford Handbook of Happiness. Oxford University, USA, pp: 733-750.

20. Gagné M, Deci EL (2005) Self-determination theory and work motivation. Journal of Organizational Behavior 26(4): 331-362.

21. Warr PB, Clapperton G (2010) The joy of work? Jobs, happiness, and you. Routledge/Taylor \& Francis Group, New York, USA

22. Gaki E, Kontodimopoulos N, Niakas D (2013) Investigating demographic, workrelated and job satisfaction variables as predictors of motivation in Greek nurses. Journal of Nursing Management 21(3): 483-490.

23. Koch SH, Proynova R, Paech B, Wetter T (2014) The perfectly motivated nurse and the others: work place and personal characteristics impact preference of nursing tasks. Journal of Nursing Management 22(8): 1054-1064.

24. Bonsdorff ME (2011) Age-related differences in reward preferences. The International Journal of Human Resource Management22(6): 12621276.

25. Global Health Workforce Alliance. Guidelines: Incentives for health professionals. Geneva: World Health Organization 2008.

26. Mc Pake B, Maeda A, Araújo EC, Lemiere C, El Maghraby, et al. (2013) Why do health labour market forces matter? Bulletin of the World Health Organization 91(11): 841-846.

27. Rosner B (1999) Fundamentals of Biostatistics: Solutions Manual (5 $5^{\text {th }}$ edn).

28. WarrP, Cook J \& Wall T (1979) Scales for the measurement of some work attitudes and aspects of psychological well-being. Journal of Occupational Psychology 52(2): 129-148.

29. Moody RC, Pesut DJ (2006) The motivation to care: Application and extension of motivation theory to professional nursing work. Journal of Health Organization and Management 20(1): 15-48.

30. International Council of Nurses (ICN) (2013) ICN Position Statement: Scope of nursing practice. Geneva, Switzerland.

31. Abdel El, Halem GE, El Hawashy ZI, Gamal El, Dein AA, et al. (2011) Undergraduate Male Nursing Students' Perception about the Image of the Nursing Profession. Journal of American Science 7(3): 614-623

32. De Cooman R, De Gieter S, Pepermans R, Du Bois C, Caers R, et al. (2008) Freshmen in nursing: job motives and work values of a new generation. Journal of Nursing Management 16(1): 56-64.

33. Abdel Kader AM, Mohamed EA, Abood SA (2012) Perception of Nurse Interns about Clinical Assignment Preparation Requirements. Journal of American Science 8(12): 676-682.
34. Hackman JR, Oldham GR (1980) Work redesign. Reading, AddisonWesley, USA.

35. Weldegebriel Z, Ejigu Y, Weldegebreal F, Woldie M (2016) Motivation of health workers and associated factors in public hospitals of West Amhara, Northwest Ethiopia. Dove Press Ltd (10): 159-169.

36. Cai CF, Zhou ZK, Yeh H, Hu J (2011) Empowerment and its effects on clinical nurses in central China. International Nursing Review 58(1): 138-144.

37. Freitas AR, Carneseca EC, Paiva CE, Paiva BS (2014) Impact of a physical activity program on the anxiety, depression, occupational stress and burnout syndrome of nursing professionals. Rev Latino-Am Enfermagem 22(2): 332-336.

38. Danil S, Pieter S, Abigail B (2015) Intrinsic motivations and the nonprofit health sector: evidence from Ethiopia.

39. Jacobi N (2011) Extrinsic factors affecting health worker motivation in the context of task shifting: experiences of VCT counselors in Ethiopia [MPH Capstone paper]. Johns Hopkins University 18-86.

40. Tummers LG, Den DulkL (2013) The effects of work alienation on organizational commitment, work effort and work-to-family enrichment. J Nurs Manag 21(6): 850-859.

41. Battistelli A, Galletta M, Porthoghese I, Vandenberghe C (2013) Mindsets of commitment and motivation: interrelationships and contribution to work outcomes. J Psychol147(1): 17-48.

42. Dave DS, Dotson MJ, Cazier JA, Chawla SK, Badgett TF (2011) The impact of intrinsic motivation on satisfaction with extrinsic rewards in a nursing environment. Journal of Management \& Marketing in Healthcare 4(2): 101-107.

43. Baldwin JN (2016) Winning at following; secrets to success in supporting roles. USA. Liberary of Congress Cataloging. pp.180-190.

44. Xu W (2015) Main factors influencing nurse job satisfaction a follow-up study. Published Master of Science in Business Administration at ISCTEUniversity Institute of Lisbon. pp. 1-62.

45. Pillay R (2009) Work satisfaction of professional nurses in South Africa: a comparative analysis of the public and private sectors. Bio-Med Central, Human Resources for Health pp. 7:15.

46. Almalki MJ, Gerald GF, Clark M (2012) Quality of work life among primary health care nurses in the Jazan region, Saudi Arabia: a crosssectional study. Bio Med Central, Hum Resour Health pp. 10: 30.

47. AbuRuz ME (2014) A comparative study about the impact of stress on job satisfaction between Jordanian and Saudi nurses. European Scientific Journal10 (17): 162-172.

48. Stacey RD (2011) Strategic management and organizational dynamics: The challenge of complexity to ways of thinking about organizations. (6th edn), Financial Times Prentice Hall in Harlow, USA.

49. Parveen M (2015) Healthcare Industry in Saudi Arabia: Demographics Effect on Job Satisfaction and Retention. International Journal of Business and Social Science 6(9): 78-88.

50. Lamadah S, Sayed H (2014) Challenges Facing Nursing Profession in Saudi Arabia. Journal of Biology, Agriculture and Healthcare 4(7): 20-25. 